\title{
Verbal Interventions and Exchange Rate Policies: The Case of Swiss Franc Cap*
}

\author{
Nikola Mirkov ${ }^{\dagger}$ \\ Igor Pozdeev \\ Swiss National Bank \\ University of St. Gallen \\ Paul Söderlind ${ }^{\S}$ \\ University of St. Gallen
}

August 14, 2018

\begin{abstract}
We ask whether verbal interventions by the Swiss National Bank (SNB) affected market beliefs in the desired direction during the period from 2011 to 2015, when the SNB imposed a cap on the Swiss franc at 1.20 against the euro. A verbal intervention was a speech by a member of the SNB Governing Board containing the wording "utmost determination" and/or "unlimited quantities". We show that these verbal interventions lowered option-based measures of uncertainty regarding the future value of euro/Swiss franc exchange rate and steered market beliefs toward franc depreciation, therefore reinforcing the credibility of the Swiss franc cap.

Keywords: Swiss franc; options; FX liquidity; verbal interventions JEL Classifications: E58, E44, G12
\end{abstract}

*The views expressed in this paper are those of the authors, and do not necessarily reflect the views of the Swiss National Bank. We would like to thank Katrin Assenmacher, Christoph Meyer, Nicolas Stoffels, Attilio Zanetti, Carlos Lenz, Nina Karnaukh, Thomas Nellen, Hanno Lustig, Adreas Fischer, the participants of the 5th Workshop on financial determinants of exchange rates and the 20th ICMAIF conference for their valuable comments.

${ }^{\dagger}$ Corresponding author: Nikola Mirkov, Swiss National Bank, Börsenstrasse 15, 8001 Zurich, Switzerland, E-mail: nikola.mirkov@snb.ch

$\ddagger$ Igor Pozdeev, University of St. Gallen, Unterer Graben 21, 9000 St. Gallen, Switzerland, E-mail: igor.pozdeev@unisg.ch

§Paul Söderlind, University of St. Gallen, Unterer Graben 21, 9000 St. Gallen, Switzerland, E-mail: paul.soderlind@unisg.ch 


\section{Introduction}

Verbal interventions are generally shown to be a valuable tool in conducting foreign exchange policies. Beine et al. (2009) finds that issuing commentary statements during foreign exchange interventions tends to reduce exchange rate volatility. Fratzscher (2008) shows that communication policies by the central banks of the US, euro area and Japan have influenced the exchange rates in the desired direction. Burkhard and Fischer (2009) find that repeated references of non-sterilized interventions by the Swiss National Bank (SNB) during the period 2002 - 2005 depreciated the domestic currency. On the other hand, comments and verbal interventions by officials can sometimes trigger sudden exchange rate jumps and hence temporarily increase market uncertainty, see Dewachter et al. (2014). Our study adds to this literature by examining the case of the Swiss franc cap against the euro enforced by the SNB during the period from September 2011 to January 2015.

In particular, the SNB set a 1.20 cap on the Swiss franc against the euro to avert the risk of deflation resulting from a "massive overvaluation of the Swiss franc", see SNB (2011). The franc had appreciated significantly against the euro and the US dollar in the months prior to the announcement amid the intensifying euro area crisis. The appreciation posed a threat to the small open Swiss economy. With the policy rate already being at zero, the SNB decided to announce a minimum euro/Swiss Franc exchange rate by promising to buy foreign currency in unlimited quantities if necessary.

In principle, a commitment to keeping the domestic currency low is always credible because a central bank can print unlimited amount of its own currency to buy foreign exchange.1 However, as the balance sheet of the central bank grows in size and becomes increasingly volatile, the central bank becomes exposed to various financial risks. Excessive volatility could lead to significant balance sheet losses and even to negative equity positions. As noted by Danthine (2012) and Jordan (2011), this is not a problem in the short term but could generate doubts regarding credibility of the policy in the long term.

\footnotetext{
${ }^{1}$ Which is different from a situation in which the central bank is buying its own currency and selling foreign exchange in a hope that its reserves will not deplete before the goal is achieved.
} 
In this paper, we ask whether SNB's verbal interventions reinforced the credibility of the Swiss franc cap by affecting the market beliefs in the desired direction. We consider a verbal intervention to be a speech made by a member of the SNB Governing Board that contained the wording "utmost determination" and/or "unlimited quantities" when discussing the Swiss franc cap. The market beliefs we analyse are measured in three different ways: the perceived uncertainty and skewness of the euro/Swiss franc rate distribution (both extracted from option prices), and market (il)liquidity measured by bid-ask spreads.

We find that SNB's verbal interventions reinforced the Swiss franc cap. They significantly reduced perceived uncertainty of the future euro/Swiss franc rate and had a positive effect on the skewness of the exchange rate distribution, that is, steering market beliefs towards a franc depreciation. The verbal interventions also had a positive effect on market liquidity by reducing the average bid-ask spread of the Swiss franc against a number of currencies. All in all, they affected market beliefs in the desired direction and, more generally, have shown that verbal interventions can be useful in the implementation of foreign exchange policies.

Several papers study the period when the SNB imposed the cap on the Swiss franc cap against the euro. Janssen and Studer (2014) employ the Krugman (1991) model to show that market expectations that the SNB will intervene on the foreign exchange market if the euro/Swiss franc surpasses the announced bounds was most of the time sufficient to stabilize the euro/Swiss franc rate during the cap enforcement. Hertrich and Zimmermann (2017) explore the credibility of the Swiss franc cap and find that the cap was never perfectly credible, as the estimated probability of the euro/Swiss franc exchange rate being below 1.20 was high. Hanke et al. (2015) and Jermann (2017) report increasingly lower estimates of the break probability and conclude that the market's confidence in the SNB's commitment increased over time, especially from late-2012 until the end of their samples. We show in the data section that the latter result might be partially driven by a general downward trend in the global uncertainty in the FX market during the same period.

The remainder of the paper is organized as follows: section 2 describes the dataset, section 3 explains how we measure the effect of verbal interventions and section 4 reports our findings. 


\section{Data}

The section describes the data set. It includes option data, SNB's verbal interventions, various financial market variables, and liquidity data from the currency spot markets.

\subsection{Option data}

The option data comprise 9 implied volatilities on the following instruments: 35-, 25-, 15- 10-delta risk reversals and butterflies, as well as a delta-neutral straddle. We use composite indicative quotes from Bloomberg, compiled daily at 17:00 New York time. The maturities in the sample are 1, 3, 6, 9 and 12 months and the period for our main sample is 6 September 2011 until 15 January 2015, when the euro/Swiss franc cap was in place.

These instruments, together with the spot exchange rate and riskfree rates (proxied by LIBOR rates from Bloomberg) are used to calculate implied volatilities and strike prices for nine different (plain vanilla) call options for each maturity (see Malz, 2014 and Wystup, 2006). Figure 1 illustrates the available strike prices for the 1-month and 12-month horizons.

The span of strike prices changes over time, being considerable in mid 2012 but more modest in mid 2014. In fact, the currency option market is organized in such a way that a higher perceived uncertainty about the future euro/Swiss franc leads to a wider span of traded strike prices. Except for the two shortest horizons (1- and 3-month), there are almost always several strike prices below 1.20.

Further analysis (not tabulated) suggests that the liquidity of these instruments was good during the sample period (for instance, trading costs were arguably lower in 2014 than in either 2009 and 2016).

The prices of options are most often expressed in terms of the option-implied volatility, obtained by inverting the Black-Scholes formula. As an illustration, Figure 2 shows the implied volatilities for the 3 -month horizon. Implied volatilities for low 
strike prices were particularly high at the inception of the Swiss franc cap and in 2012, normalizing in 2013 and staying relatively low until the end of cap enforcement.

\subsubsection{Measuring uncertainty}

To measure the perceived market uncertainty about future levels of the euro/Swiss franc spot exchange rate, we use two different methods: (a) the implied volatility of the call option with a strike price closest to the spot exchange rate ("at the money"); and (b) the square root of the model-free implied variance (see Jiang and Tian, 2005) which is (loosely speaking) a weighted average of all implied volatilities. Both measures can be interpreted as the market's subjective beliefs about (annualized) volatility over the period until maturity. The second measure is used for robustness analysis.

The uncertainty measure from the first method is illustrated (for the 3-month horizon only) in Figure 3. As a comparison, we also plot an uncertainty measure for the global currency markets excluding the Swiss franc (see below for a precise definition). Interestingly, the euro/Swiss franc uncertainty appears to be strongly linked to the global currency market uncertainty. Both experience a relatively steady downward trend during the period of cap enforcement. This stylized feature in the data might be driving partially the results of the previous studies, who estimate that the probability of SNB discontinuing the cap was falling over time, see for example Hertrich and Zimmermann (2017). Figure 3 also shows considerable idiosyncratic movements in the euro/Swiss franc uncertainty, for instance, in early 2013.

\subsubsection{Measuring skewness}

To measure the market's perceived skewness of the distribution of the future euro/Swiss franc rate, we apply two related methods: (a) the implied volatility of options with high strike prices (above the spot rate) minus that of options with low strike prices (this is the average risk reversal); and (b) the model free upside standard deviation minus the downside standard deviation. Both measures can be interpreted as the "tilt" of the market beliefs: towards a higher exchange rate (positive skewness) or 
a lower one. Again, the second measure is used for robustness analysis.

The skewness measure from the first method is illustrated in Figure 3 . It was mainly negative at the beginning of the cap period, corresponding to high implied volatilities of options with low strike prices as seen in Figure 2. It started drifting upwards in autumn 2012 and remained high throughout most of 2013, but then started drifting downwards in December 2013 (on 5th December, ECB decided to keep its policy rates unchanged, but reiterated its forward guidance that key ECB rates are expected to remain low "for an extended period of time."). It turned slightly negative in late 2014.

\subsection{Liquidity data}

We study bid-ask spreads of the major currency pairs involving the Swiss franc, but excluding the euro. In general, high bid-ask spreads tend to be related to uncertainty and asymmetric information. In the case of the euro/Swiss franc cap, it can also be conjectured that an expected lifting of the Swiss franc cap would make liquidity providers cautious of an upcoming large-scale rebalancing - thus prompting them to widen the bid-ask spreads.

Our analysis of liquidity uses bid and ask spot quotes of the 9 most traded currency pairs against the Swiss franc: AUD, CAD, NZD, GBP, JPY, USD, NOK, SEK and DKK. We exclude the euro/Swiss franc since the SNB is a dominant player on that market and was known to intervene heavily.

Similar to option data, we use the composite indicative bid and ask quotes (from Bloomberg) compiled at 17:00 New York time. We focus on the de-seasonalized weighted average of the bid-ask spreads of the nine currency pairs. ${ }^{2}$ The data is de-seasonalized by removing month, week and weekday components.

\footnotetext{
${ }^{2}$ The weight for each currency pair is the share of its base currency in global foreign exchange market turnover in 2013 as taken from the BIS Triennial Central Bank Survey (http://www.bis.org/publ/rpfx13.htm). For instance, the share of all USDXXX pairs is $87 \%$, that of all JPYXXX pairs is $23 \%$, and so forth. We normalize the weights such that they sum up to one.
} 
The liquidity data is illustrated in Figure 4. The bid-ask spreads are very volatile, so the figure also shows a moving average: before (after) 15 January 2015 it is a backward (forward) looking 10-day moving average. Overall, the spreads appear to follow the same pattern as the uncertainty measures discussed before.

\subsection{SNB's communications}

Announcing the decision to impose a cap of 1.20 on the Swiss Franc against the euro, the SNB pledged to "enforce this minimum rate with the utmost determination and [...] buy foreign currency in unlimited quantities." These keywords were subsequently used in a variety of speeches by the members of the SNB Governing Board. We define a verbal intervention to be a speech made by a member of the SNB Governing Board that used these key words.

There were 26 such verbal interventions during the period from September 6, 2011, to January 14, 2015, see the left panel of Table 1. Most of these were delivered by Thomas Jordan, four of them by Fritz Zurbrügg, three of them by Jean-Pierre Danthine, and one of them by Philipp Hildebrand. Several speeches on the same day are counted as one event. The empirical analysis uses these 26 dates as dummy variables in regressions of either uncertainty, skewness or liquidity. On 7 occasions (in June and December), the speech was presenting the regular "Monetary Policy Assessments" (henceforth MPA). In later sections, we split the verbal intervention dummy into one variable for MPA dates and another for the rest.

A second dummy variable indicates the 7 MPAs that were communicated by press releases (March and September), not by speeches. They all contain the "utmost determination" or "unlimited quantities" keywords. See the mid panel of Table 1 for details.

Finally, a third dummy variable indicates the 18 policy related speeches that did not contain the "utmost determination" or "unlimited quantities" keywords, see the mid panel of Table 1. Only a few non-policy speeches are excluded, for instance, the 100 year celebration of the SNB office building in Berne. 


\subsection{Other data}

The dataset includes a number of financial market variables that we control for when regressing uncertainty, skewness or liquidity on SNB's verbal interventions. First, we collect major announcements and regular policy decisions by the ECB that might have considerably affected the option market for the euro/Swiss franc rate, see the right panel of Table 1. In addition, our dataset includes the TED spread from the Federal Reserve Bank of St. Louis, the 5-year European sovereign CDS spread from Bloomberg, a measure of global currency market uncertainty mentioned before (the cross-sectional average of the square root of model-free implied variance, see Jiang and Tian (2005), of USD exchange rates of G10 currencies excluding the CHF), the 10-year US term premium of Kim and Wright (2005) from the Federal Reserve's official website, and the spot euro/Swiss franc franc exchange rate from Bloomberg.

\section{Empirical strategy}

\subsection{Regressions}

We run the following type of regression of the $1+n$ day change of uncertainty (or skewness or liquidity)

$$
y_{t+n}-y_{t-1}=\alpha+\beta d_{t}+\delta^{\prime} D_{t}+\gamma^{\prime}\left(X_{t+n}-X_{t-1}\right)+\varepsilon_{t+n} .
$$

In these regressions, $y_{t}$ is the uncertainty (or skewness or the average bid-ask spread) on day $t, d_{t}$ is a dummy variable that takes the value of one on the day of the verbal SNB intervention (speeches that included the keywords "utmost determination" or "unlimited quantities") and zero otherwise, $D_{t}$ is a vector of two dummy variables for the MPAs communicated by press releases and other SNB speeches (see Table 1 for the dummies), and $X_{t}$ is a vector of control variables. The latter includes the dummy for ECB policy decisions, the TED spread, the Eurozone CDS spreads, global currency market volatility, the 10-year US term premium and the spot euro/Swiss franc rate. 


\subsection{Event studies}

The regression results are reinforced by an event study approach along the lines of Fama et al. (1969). To study the evolution of the effect the verbal interventions had on the uncertainty and skewness, we calculate daily changes in the two measures and define the "normal" changes as those prevailing on average over day $t-45$ to day $t-1$, where $t$ is the day of a speech (similar to Brown and Warner (1980)) $!^{3}$ If two speeches are less than 45 days apart, we reduce the estimation window to avoid overlap.

The "abnormal" change on day $t$ is then the actual change minus the "normal" change. For each day, we compute the cumulative abnormal change in the uncertainty and skewness $n=1,2, \ldots, 5$ days forward. We use the standard deviation on days $t-45$ to $t-1$ (or in the shorter interval as above) to gauge significance of the the average (over all speeches) cumulative abnormal change.

\section{Results}

This section is structured as follows. We first report the results of estimated effects of verbal interventions on uncertainty. Then, we show the results for skewness of the implied distribution and for market liquidity. Finally, we show and discuss the robustness checks we performed.

\subsection{Verbal interventions and uncertainty}

The regression results in Table 2 show that SNB's verbal interventions significantly reduced the uncertainty regarding the future value of the euro/Swiss franc rate during the period of cap enforcement. The table shows the regression coefficients and $t$-statistics for the two-day change of uncertainty $(n=1$ in equation 1). The $t$-statistics are based on a Newey-West approach with a bandwidth of 2 , but using

\footnotetext{
${ }^{3}$ Changing the estimation window (for instance, to 22 days) has a negligible impact on the results.
} 
a Hansen-Hodrick approach gives very similar results.

The effect is stronger for shorter maturities: it is -0.20 for the 1 -month horizon and -0.12 for the 12 -month horizon. This might suggest that the short-term market beliefs are more responsive to news than long-term beliefs (this is supported also by the pattern found for the control variables, discussed below). Comparing the coefficients with the movements of uncertainty in Figure 3 , suggests that the economic effect is non-trivial but not very large: uncertainty jumps from $5 \%$ to $6 \%$ (or similarly) are not unusual in the figure, but the verbal intervention would only account for up to $0.2 \%$.

The MPAs, communicated by press releases and containing the keywords, also have strongly negative effects. For longer maturities, their effect is twice as larger relative to verbal interventions. Interestingly, this pattern does not show up in the regressions for skewness, see the next section $4^{4}$ Other SNB speeches that did not contain the keywords "utmost determination" or "unlimited quantities" had no effect on uncertainty.

For the control variables, both the global FX market volatility and the spot euro/Swiss franc exchange rate have positive and strongly significant coefficients. Similarly, the announcements made by the ECB tend to increase euro/Swiss franc uncertainty, but the coefficients are significant only for the 3,6 and 9 month horizons. In contrast, TED spread and the average CDS spread across EU countries, have insignificant coefficients. Similarly to the results for the verbal interventions, the slope coefficients of the control variables tend to have have larger magnitudes for the shorter horizons.

Table 3 shows results for one-day changes $\left(y_{t}-y_{t-1}\right)$ to six-day changes $\left(y_{t+5}-y_{t-1}\right)$. For brevity, only the coefficients for SNB's verbal intervention dummies are shownwith indicators of statistical significance. It seems as if the effect of the speeches builds up during a few trading days, but starts to evaporate after four days. The statistical significance is stronger for the longer maturities.

To support these findings, Figure 5 illustrates the event study. It shows the average (across speeches) cumulative abnormal changes in the uncertainty at different days

\footnotetext{
${ }^{4}$ See also the section 4.4 , where we split all the verbal interventions to those made during the MPAs and the rest.
} 
after a speech, as well as a 95\% confidence interval around zero. In line with the regression findings, we see that the same day's change in uncertainty is negative and marginally significant. During the next three days, uncertainty continues to decline significantly. The magnitude of the changes are similar to those of the regression coefficients, which is explained by the fact that the verbal intervention dummy is virtually uncorrelated with the other regressors in equation (1), with correlations between -0.07 and 0.02 .

\subsection{Verbal interventions and skewness}

The regression results in Table 4 show that SNB's verbal interventions steered the market beliefs toward depreciation of the Swiss franc by having a positive and statistically significant effect on skewness. The table reports regression results for the two-day change of skewness. The regressors are the same as before, except that uncertainty is added to the set of regressors in order to control for any direct effects of uncertainty on skewness. Similarly to before, the economic effect is not large, but still strongly statistically significant.

The results also show that the MPAs communicated by press releases had a strong positive effect only on the shortest maturity. The rest of the maturities were basically unaffected. Other speeches (not containing the key words) have no effects.

Among the control variables, troubles in the euro zone as measured by the euro zone CDS spreads and global currency market uncertainty tilt the beliefs towards a lower euro/Swiss franc rate, whereas a higher current spot rate does the opposite. In contrast, ECB announcements, the TED spread and the euro/Swiss franc uncertainty have no (or only small) significant effect.

Table 5 shows that the effect of SNB's verbal interventions accumulates for a few days. The event study reported in Figure 6 shows the same pattern. 


\subsection{Verbal interventions and market liquidity}

Table 6 reports regression results for the two-day change of bid-ask spreads. The coefficient on SNB's verbal interventions is negative and significant on the $8 \%$ level. The fit of this regression is poor (low $R^{2}$ ) as should be expected from such volatile data. It can also be shown (not tabulated) that the results for changes over fewer $(n=0)$ or more $(n \geq 2)$ are similar. This lends some support to the earlier results that the verbal interventions contributed to lower market uncertainty.

\subsection{Extended regressions}

News conferences of the SNB on the occasions of Monetary Policy Assessments (MPAs) represent important market events globally. The introductory remarks by the members of the Governing Board during these news conferences likely enjoyed a higher media coverage relative to other speeches. Therefore, we split the verbal interventions into those made during the MPAs and those of other days and study their effects separately, see Table 7. As expected, the effects of MPA-interventions are much stronger and more statistically significant than non-MPA speeches.

As a robustness check, we re-run the regressions by using other measurements of the dependent variable, namely model-free uncertainty and skewness. Table 8 shows that the regression results remain broadly unchanged.

Finally, we investigate the stability over time of the regression results. We re-run the previous regressions but add a dummy for the first verbal intervention, then (in a second regression) dummy for the 2nd verbal intervention instead, and so forth until the last (26th) intervention. The results are illustrated in Figure 7, which show the sum of the average effect (coefficient on the previous dummies for SNB's verbal interventions) and the "extra" effect on each intervention days. On most days the effect is negative and often significantly so. There are only three days of significantly positive effects: the first and last intervention days and also the 16 November 2012. 


\section{Conclusion}

We examine whether the use of the wording "utmost determination" and/or "unlimited quantities" by the members of the SNB Governing Board significantly affected market beliefs during the period from 2011 to 2015 when the Swiss franc was capped at 1.20 against the euro.

The results show that verbal interventions by the SNB reduced uncertainty regarding the future value of euro/Swiss franc spot exchange rate and had a positive effect on skewness of the option-implied euro/Swiss franc distribution. Therefore, they reinforced the Swiss franc cap and, more generally, provided further evidence the verbal interventions can be useful in the implementation of exchange rate policies. 


\section{References}

Beine, Michel, Gust Janssen, and Christelle Lecourt (2009) "Should central bankers talk to the foreign exchange markets?," Journal of International Money and Finance, Vol. 28, No. 5, pp. 776-803, September.

Brown, Stephen J. and Jerold B. Warner (1980) "Measuring Security Price Performance," Journal of Financial Economics, Vol. 8, pp. 205-258.

Burkhard, Lukas and Andreas M. Fischer (2009) "Communicating policy options at the zero bound," Journal of International Money and Finance, Vol. 28, No. 5, pp. 742-754, September.

Danthine, Jean-Pierre (2012) "Monetary policy is not almighty," Speech at "Journée Solutions Bancaires", No. Geneva, 31 May 2012.

Dewachter, Hans, Deniz Erdemlioglu, Jean-Yves Gnabo, and Christelle Lecourt (2014) "The intra-day impact of communication on euro-dollar volatility and jumps," Journal of International Money and Finance, Vol. 43, No. C, pp. 131-154.

Fama, Eugene F., Lawrence Fisher, Michael Jensen, and Richard Roll (1969) "The Adjustment of Stock Prices of New Information," International Economic Review, Vol. 10, pp. 1-21.

Fratzscher, Marcel (2008) "Communication and exchange rate policy," Journal of Macroeconomics, Vol. 30, No. 4, pp. 1651-1672, December.

Hanke, Michael, Rolf Poulsen, and Alex Weissensteiner (2015) "Where Would the EUR/CHF Exchange Rate be Without the SNB's Minimum Exchange Rate Policy?" Journal of Futures Markets, Vol. 35, No. 12, pp. 1103-1116.

Hertrich, Markus and Heinz Zimmermann (2017) "On the Credibility of the Euro/Swiss Franc Floor: A Financial Market Perspective," Journal of Money, Credit and Banking, Vol. 49, No. 2-3, pp. 567-578.

Janssen, Alexandra and Rahel Studer (2014) "The Swiss franc's honeymoon," ECON - Working Papers 170, Department of Economics - University of Zurich.

Jermann, Urban J. (2017) "Financial Markets' Views about the Euro-Swiss Franc Floor," Journal of Money, Credit and Banking, Vol. 49, No. 2-3, pp. 553-565.

Jiang, George J. and Yisong S. Tian (2005) "The Model-Free Implied Volatility and Its Information Content," The Review of Financial Studies, Vol. 18, No. 4, p. 
1305.

Jordan, Thomas (2011) "Does the Swiss National Bank need equity?" StatistischVolkswirtschaftliche Gesellschaft, No. Basel, 28 September 2011.

Kim, Don H. and Jonathan H. Wright (2005) "An Arbitrage-Free Three-Factor Term Structure Model and the Recent behavior of Long-Term Yields and DistantHorizon Forward Rates."

Krugman, Paul R. (1991) "Target Zones and Exchange Rate Dynamics," The Quarterly Journal of Economics, Vol. 106, No. 3, pp. 669-682.

Malz, Allan M. (2014) "Simple and reliable way to compute option-based riskneutral distributions," Staff Reports 677, Federal Reserve Bank of New York.

Newey, Whitney K. and Kenneth D. West (1987) "A Simple, Positive Semi-Definite, Heteroskedasticity and Autocorrelation Consistent Covariance Matrix," Econometrica, Vol. 55, No. 3, pp. 703-708.

SNB (2011) "Swiss National Bank sets minimum exchange rate at CHF 1.20 per euro," Communications, No. September 2011.

Wystup, Uwe (2006) FX Options and Structured Products: Wiley. 
Tables and Figures 
Table 1: List of the SNB's verbal interventions and ECB announcements. The first column (SNB verbal interventions) of the table reports the speeches by the members of the SNB's Governing Board used to create the dummy variable $d_{t}$ in equation (1). The speeches presenting the "Monetary Policy Assessment" are marked "MPA". It also reports other SNB speeches, SNB MPA press releases (both in column 2) and the regular monetary policy decisions by the ECB and several key policy announcements (ECB, column 3) used to create the dummies in $D_{t}$ in equation (1).

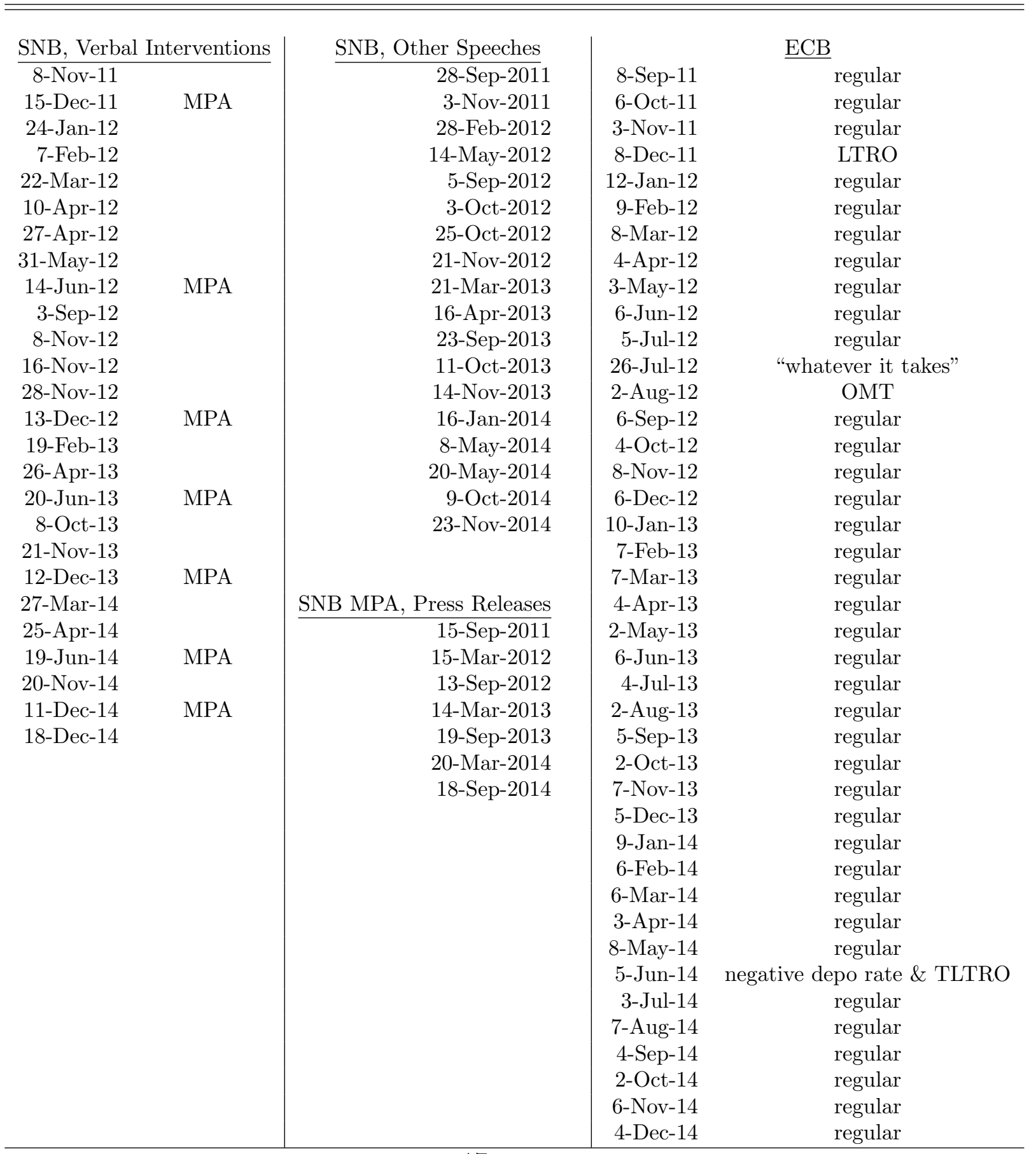


Table 2: The SNB's verbal interventions and market uncertainty. The table reports estimated coefficients of equation (1) and t-stats (in parentheses) for $n=1$. The dependent variables are the 2-day changes of uncertainty (implied volatility at the money) from options with 1, 3, 6, 9 and 12 months to expiration (different columns). The right-hand variables are (from top to bottom) a dummy for SNB's verbal interventions, three other dummy variables: SNB "Monetary Policy Assessment" (MPA) press releases, other SNB speeches and ECB key policy decisions and also two-day changes of a number of control variables: the TED spread, the European sovereign CDS spread, a measure of global FX market uncertainty (FX vol), 10-year term premium on US Treasuries (10y US TP), and the the spot euro/Swiss franc rate. The intercept is not reported. The t-stats are estimated using the Newey and West (1987) approach with 2 lags. The sample goes from 6 September 2011 to 14 February 2015.

\begin{tabular}{lccccc}
\hline \hline & $1 \mathrm{~m}$ & $3 \mathrm{~m}$ & $6 \mathrm{~m}$ & $9 \mathrm{~m}$ & $12 \mathrm{~m}$ \\
\hline \multirow{2}{*}{ Verbal interventions } & -0.20 & -0.14 & -0.12 & -0.12 & -0.12 \\
& $(-2.27)$ & $(-2.02)$ & $(-2.51)$ & $(-2.67)$ & $(-2.68)$ \\
MPA (press release) & -0.33 & -0.24 & -0.24 & -0.23 & -0.25 \\
& $(-2.01)$ & $(-2.09)$ & $(-2.53)$ & $(-2.86)$ & $(-3.16)$ \\
Other speech & -0.04 & -0.06 & -0.05 & -0.05 & -0.04 \\
& $(-0.34)$ & $(-0.68)$ & $(-0.76)$ & $(-0.92)$ & $(-0.91)$ \\
ECB & 0.12 & 0.16 & 0.09 & 0.07 & 0.05 \\
& $(1.37)$ & $(2.63)$ & $(1.97)$ & $(1.80)$ & $(1.59)$ \\
TED & -0.87 & -0.60 & -0.65 & -0.41 & -0.11 \\
& $(-0.66)$ & $(-0.61)$ & $(-0.78)$ & $(-0.56)$ & $(-0.15)$ \\
EU CDS & -0.17 & -0.12 & 0.00 & 0.06 & 0.07 \\
FX vol & $(-0.87)$ & $(-0.74)$ & $(0.03)$ & $(0.43)$ & $(0.55)$ \\
\multirow{2}{*}{ 10y US TP } & 0.53 & 0.41 & 0.31 & 0.27 & 0.24 \\
& $(7.56)$ & $(7.35)$ & $(5.86)$ & $(5.25)$ & $(4.72)$ \\
Spot & -1.45 & -0.76 & -0.34 & -0.16 & -0.07 \\
\multirow{2}{*}{$R^{2}$} & $(-3.44)$ & $(-2.83)$ & $(-1.58)$ & $(-0.79)$ & $(-0.37)$ \\
\hline
\end{tabular}


Table 3: The dynamic effect of the SNB's verbal interventions on uncertainty. The table shows the coefficient estimates on the dummy variable for SNB's verbal inteventions in equation (1) for $n=0$ to $n=5$. The regressors and the sample are the same as in Table 2. For brevity, only the coefficients for the SNB dummy are presented. *, $* *$, and ${ }^{* * *}$ denote significance at the $10 \%, 5 \%$, and $1 \%$ levels, respectively, using t-stats estimated by the Newey and West (1987) approach with $1+n$ lags.

\begin{tabular}{llcccc}
\hline \hline Change over & $1 \mathrm{~m}$ & $3 \mathrm{~m}$ & $6 \mathrm{~m}$ & $9 \mathrm{~m}$ & $12 \mathrm{~m}$ \\
\hline$t-1$ to $t$ & -0.14 & -0.07 & $-0.08^{* *}$ & $-0.08^{* *}$ & $-0.09^{* * *}$ \\
$t-1$ to $t+1$ & $-0.20^{* *}$ & $-0.14^{* *}$ & $-0.12^{* *}$ & $-0.12^{* * *}$ & $-0.12^{* * *}$ \\
$t-1$ to $t+2$ & -0.15 & -0.10 & $-0.10^{*}$ & $-0.11^{* *}$ & $-0.12^{* * *}$ \\
$t-1$ to $t+3$ & -0.19 & -0.13 & $-0.13^{*}$ & $-0.13^{* *}$ & $-0.14^{* *}$ \\
$t-1$ to $t+4$ & -0.18 & -0.12 & $-0.15^{*}$ & $-0.14^{* *}$ & $-0.15^{* *}$ \\
$t-1$ to $t+5$ & -0.01 & -0.02 & -0.09 & -0.10 & -0.12 \\
\hline
\end{tabular}


Table 4: The SNB's verbal interventions and market skewness. The table reports estimated coefficients of equation (1) and t-stats (in parentheses) for $n=1$. The dependent variables are the 2-day changes of skewness (implied volatility of options with high strike prices minus the implied volatility of options with low strike prices). The sample and the right-hand variables are the same as in Table 2, except that the two-day change of uncertainty is added to the set of control variables. The t-stats are estimated using the Newey and West (1987) approach with 2 lags.

\begin{tabular}{lccccc}
\hline \hline & $1 \mathrm{~m}$ & $3 \mathrm{~m}$ & $6 \mathrm{~m}$ & $9 \mathrm{~m}$ & $12 \mathrm{~m}$ \\
\hline Verbal interventions & 0.04 & 0.09 & 0.10 & 0.10 & 0.11 \\
& $(1.01)$ & $(1.85)$ & $(2.12)$ & $(2.62)$ & $(2.66)$ \\
MPA (press release) & 0.18 & 0.06 & 0.07 & 0.01 & 0.01 \\
& $(1.83)$ & $(1.33)$ & $(1.39)$ & $(0.20)$ & $(0.21)$ \\
Other speech & 0.10 & 0.08 & 0.03 & 0.01 & 0.00 \\
& $(1.08)$ & $(1.15)$ & $(0.50)$ & $(0.11)$ & $(0.01)$ \\
ECB & 0.10 & -0.06 & -0.03 & -0.03 & -0.02 \\
& $(1.02)$ & $(-0.69)$ & $(-0.58)$ & $(-0.61)$ & $(-0.56)$ \\
TED & 1.31 & 0.21 & -0.78 & -0.89 & -1.61 \\
& $(1.36)$ & $(0.25)$ & $(-1.03)$ & $(-1.14)$ & $(-1.75)$ \\
EU CDS & -0.22 & -0.33 & -0.25 & -0.26 & -0.09 \\
& $(-1.28)$ & $(-2.04)$ & $(-1.90)$ & $(-2.05)$ & $(-0.48)$ \\
FX vol & -0.09 & -0.11 & -0.11 & -0.11 & -0.10 \\
10y US TP & $(-1.70)$ & $(-2.16)$ & $(-2.38)$ & $(-2.55)$ & $(-2.30)$ \\
& -0.23 & 0.14 & 0.13 & 0.19 & 0.22 \\
Spot & $(-0.57)$ & $(0.43)$ & $(0.42)$ & $(0.74)$ & $(0.87)$ \\
& 0.19 & 0.15 & 0.11 & 0.11 & 0.12 \\
Uncertainty & $(3.24)$ & $(2.84)$ & $(2.09)$ & $(2.11)$ & $(2.16)$ \\
\multirow{2}{*}{$R^{2}$} & 0.12 & 0.03 & 0.04 & 0.04 & 0.02 \\
& $(1.25)$ & $(0.34)$ & $(0.59)$ & $(0.54)$ & $(0.31)$ \\
& 0.10 & 0.09 & 0.09 & 0.10 & 0.07 \\
\hline
\end{tabular}


Table 5: The dynamic effect of the SNB's verbal interventions on skewness. The table shows the coefficient estimates on the dummy variable for SNB's verbal interventions in equation (1) for $n=0$ to $n=5$. The sample and the right-hand variables are the same as in Table 4. For brevity, only the coefficients for the SNB dummy are presented. *, $* *$, and ${ }^{* * *}$ denote significance at the $10 \%, 5 \%$, and $1 \%$ levels, respectively, using t-stats estimated by the Newey and West (1987) approach with $1+n$ lags.

\begin{tabular}{llllll}
\hline \hline Change over & \multicolumn{1}{c}{$1 \mathrm{~m}$} & $3 \mathrm{~m}$ & \multicolumn{1}{c}{$6 \mathrm{~m}$} & $9 \mathrm{~m}$ & \multicolumn{1}{c}{$12 \mathrm{~m}$} \\
\hline$t-1$ to $t$ & 0.03 & $0.04^{*}$ & $0.07^{* *}$ & $0.05^{*}$ & 0.04 \\
$t-1$ to $t+1$ & 0.04 & $0.09^{*}$ & $0.10^{* *}$ & $0.10^{* * *}$ & $0.11^{* * *}$ \\
$t-1$ to $t+2$ & 0.11 & $0.10^{*}$ & $0.11^{* *}$ & $0.09^{*}$ & 0.05 \\
$t-1$ to $t+3$ & $0.13^{*}$ & 0.09 & $0.11^{*}$ & $0.10^{*}$ & 0.09 \\
$t-1$ to $t+4$ & $0.23^{* *}$ & $0.20^{* *}$ & $0.20^{* * *}$ & $0.17^{* *}$ & $0.14^{*}$ \\
$t-1$ to $t+5$ & $0.20^{* *}$ & $0.22^{* *}$ & $0.17^{* *}$ & 0.12 & 0.10 \\
\hline
\end{tabular}


Table 6: The SNB's verbal interventions and market liquidity. The table reports estimated coefficients of equation (11) and t-stats (in parentheses) for $n=$ 1. The dependent variable is the 2-day changes of de-seasonalized average bid-ask spreads for 9 currencies against the CHF (excluding EUR), in pips. The sample and the right-hand variables are the same as in Table 2. The t-stats are estimated using the Newey and West (1987) approach with 2 lags.

\begin{tabular}{lc}
\hline \hline & Bid-ask spread \\
\hline Verbal interventions & -0.25 \\
& $(-1.73)$ \\
MPA (press release) & -0.55 \\
& $(-1.26)$ \\
Other speech & 0.26 \\
& $(0.83)$ \\
ECB & 0.41 \\
& $(1.76)$ \\
TED & -9.15 \\
& $(-3.39)$ \\
EU CDS & -0.44 \\
& $(-0.82)$ \\
FX vol & 0.33 \\
& $(2.21)$ \\
10y US TP & 0.82 \\
& $(1.03)$ \\
Spot & 0.02 \\
& $(0.14)$ \\
$R^{2}$ & 0.03 \\
\hline
\end{tabular}


Table 7: Different types of verbal interventions. The table reports estimated coefficients of equation (1) and t-stats (in parentheses) for $n=1$. The sample and structure is the same as Tables 2 and 4, except that SNB's verbal interventions are divided into two seperate dummies: speeches presenting monetary policy assessments (MPA) and on other days (non-MPA). All speeches contained the keywords "utmost determination" and "unlimited quantities." For brevity only the results for the SNB dummies are presented.

\begin{tabular}{lccccc}
\hline \hline & $1 \mathrm{~m}$ & $3 \mathrm{~m}$ & $6 \mathrm{~m}$ & $9 \mathrm{~m}$ & $12 \mathrm{~m}$ \\
\hline Uncertainty regression & & & & & \\
\hline Verbal interv. non-MPA & -0.12 & -0.13 & -0.09 & -0.08 & -0.09 \\
& $(-1.14)$ & $(-1.45)$ & $(-1.56)$ & $(-1.67)$ & $(-1.86)$ \\
Verbal interv. MPA & -0.43 & -0.15 & -0.17 & -0.20 & -0.21 \\
& $(-2.63)$ & $(-2.44)$ & $(-3.20)$ & $(-2.52)$ & $(-2.07)$ \\
MPA (press release) & -0.34 & -0.24 & -0.24 & -0.23 & -0.25 \\
& $(-2.02)$ & $(-2.09)$ & $(-2.53)$ & $(-2.87)$ & $(-3.17)$ \\
Skewness regression & & & & & \\
Verbal interv. non-MPA & 0.02 & 0.08 & 0.08 & 0.07 & 0.08 \\
& $(0.63)$ & $(1.43)$ & $(1.31)$ & $(1.57)$ & $(1.80)$ \\
Verbal interv. MPA & 0.01 & 0.07 & 0.14 & 0.17 & 0.16 \\
& $(0.08)$ & $(1.49)$ & $(2.12)$ & $(2.44)$ & $(2.39)$ \\
MPA (press release) & 0.14 & 0.05 & 0.05 & -0.00 & 0.00 \\
& $(1.59)$ & $(1.48)$ & $(1.31)$ & $(-0.06)$ & $(0.08)$ \\
\hline
\end{tabular}

Table 8: Robustness check. The SNB's verbal interventions and an alternative measure of market uncertainty and skewness. The table reports estimated coefficients of equation (1) and t-stats (in parentheses) for $n=1$. The sample and structure is the same as Tables 2 and 4 , except that the dependent variable is the model free volatility and skewness, respectively. For brevity only the results for the SNB verbal intervention are presented.

\begin{tabular}{lccccc}
\hline \hline & $1 \mathrm{~m}$ & $3 \mathrm{~m}$ & $6 \mathrm{~m}$ & $9 \mathrm{~m}$ & $12 \mathrm{~m}$ \\
\hline Uncertainty & -0.18 & -0.12 & -0.12 & -0.12 & -0.13 \\
regression & $(-2.02)$ & $(-1.67)$ & $(-2.35)$ & $(-2.71)$ & $(-2.66)$ \\
Skewness & 0.01 & 0.04 & 0.05 & 0.05 & 0.06 \\
regression & $(0.34)$ & $(1.32)$ & $(1.69)$ & $(2.20)$ & $(2.22)$ \\
\hline
\end{tabular}


Figure 1: Strike prices of the currency options. The figure shows for which strike prices our data set has (synthetic plain vanilla call and put) option prices. Only maturities of 1 month (left panel) and 12 months (right panel) are shown. The strike prices are obtained as a on-to-one mapping from the observed deltas of option contracts, following Wystup (2006).
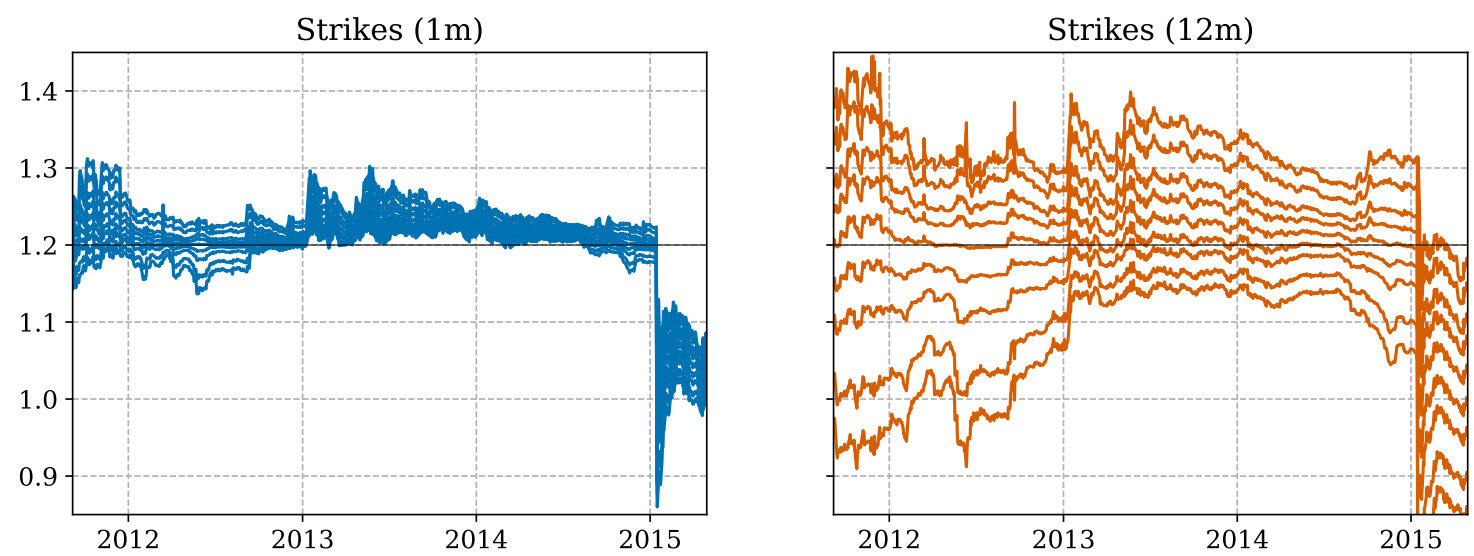
Figure 2: Implied volatilities of the currency options. The figure shows all 9 implied volatilities of the synthetic 3 -month plain vanilla call and put options on the euro/Swiss franc spot exchange rate. The upper panel covers in-the-money, and the lower panel - out-of-the money options. The volatilities are recovered from option contracts as described in Malz (2014).
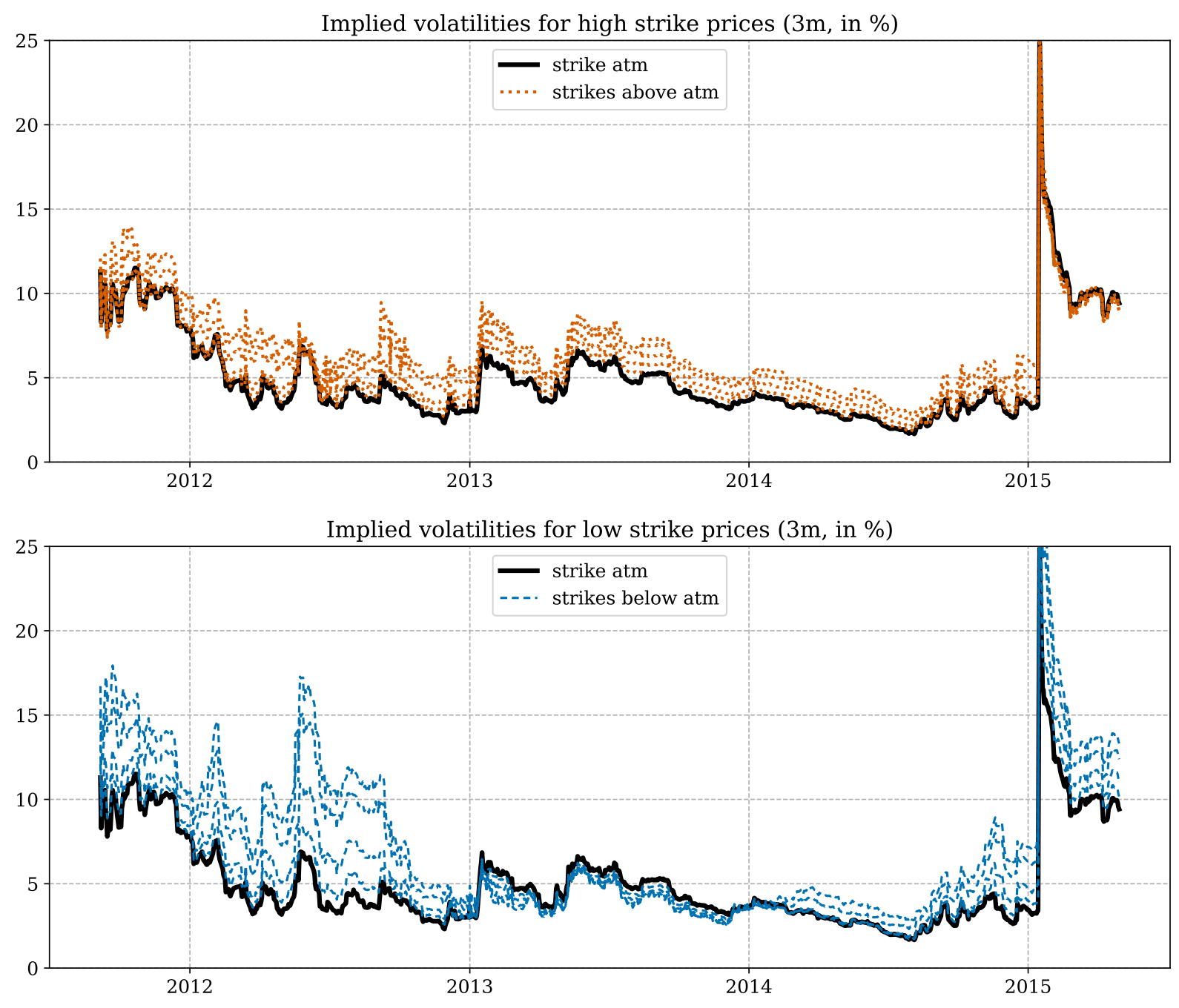
Figure 3: Uncertainty and skewness. The figure shows the 3-month uncertainty and skewness measures for the euro/Swiss franc spot exchange rate, as well as the measure for the global FX uncertainty. The uncertainty measure is the observed Black-Scholes implied volatility of the at-the-money call option; the skewness measure is calculated as the average risk-reversal implied volatility. The global FX uncertainty is defined as the average of the individual uncertainty measures for bilateral exchange rates of 9 currencies (G10 currencies except the euro) against the Swiss franc.

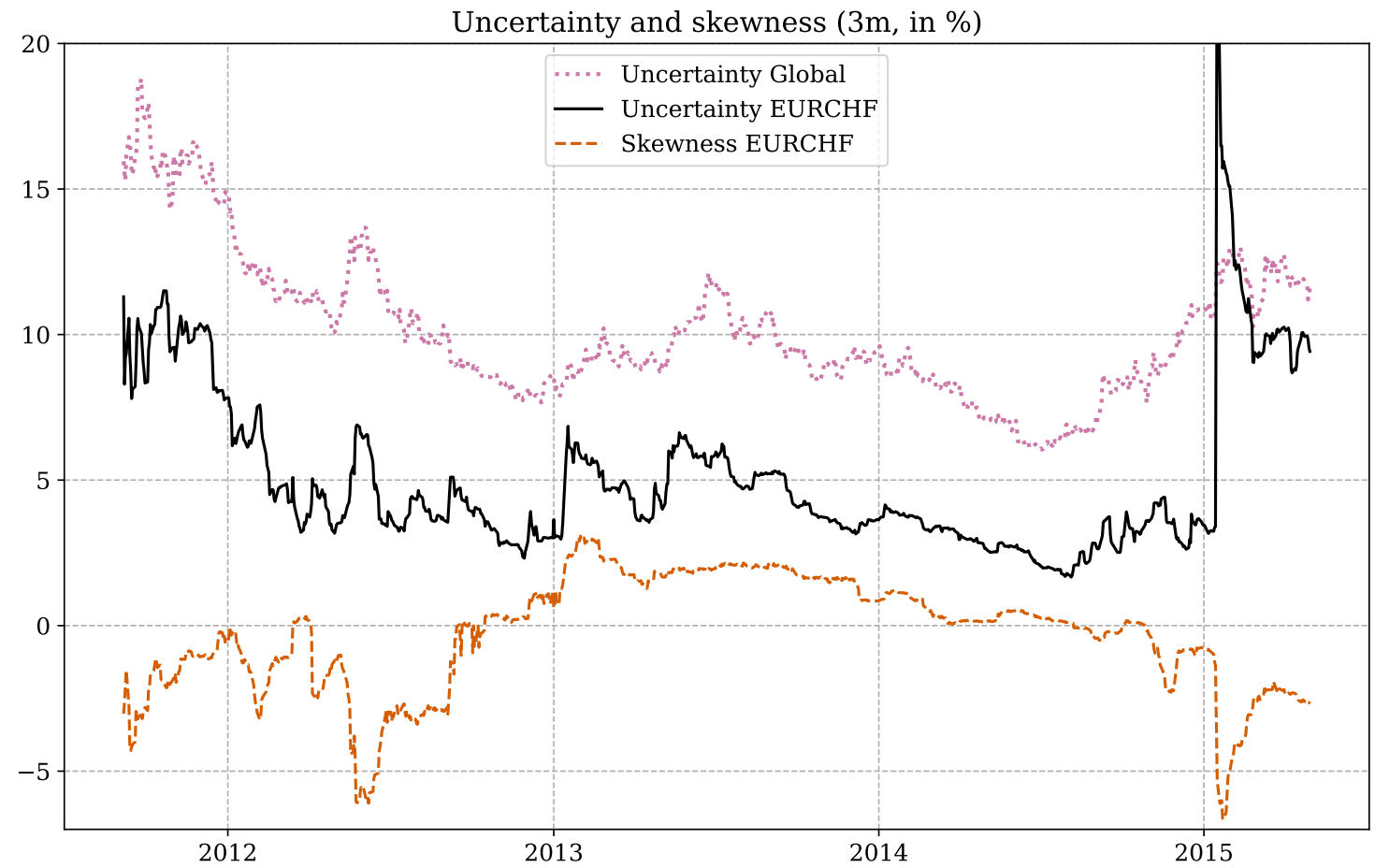


Figure 4: Bid-ask spreads. The figure shows the volume-weighted cross-sectional average spread (in pips) of bilateral exchange rates of 9 currencies (G10 currencies except the euro) against the Swiss franc, and the 10-day moving average thereof. The data is de-seasonalized by removing the month, week and weekday components. The blue shaded area - the $95 \%$ confidence interval around this value, calculated under assumption that daily average spread values are i.i.d.

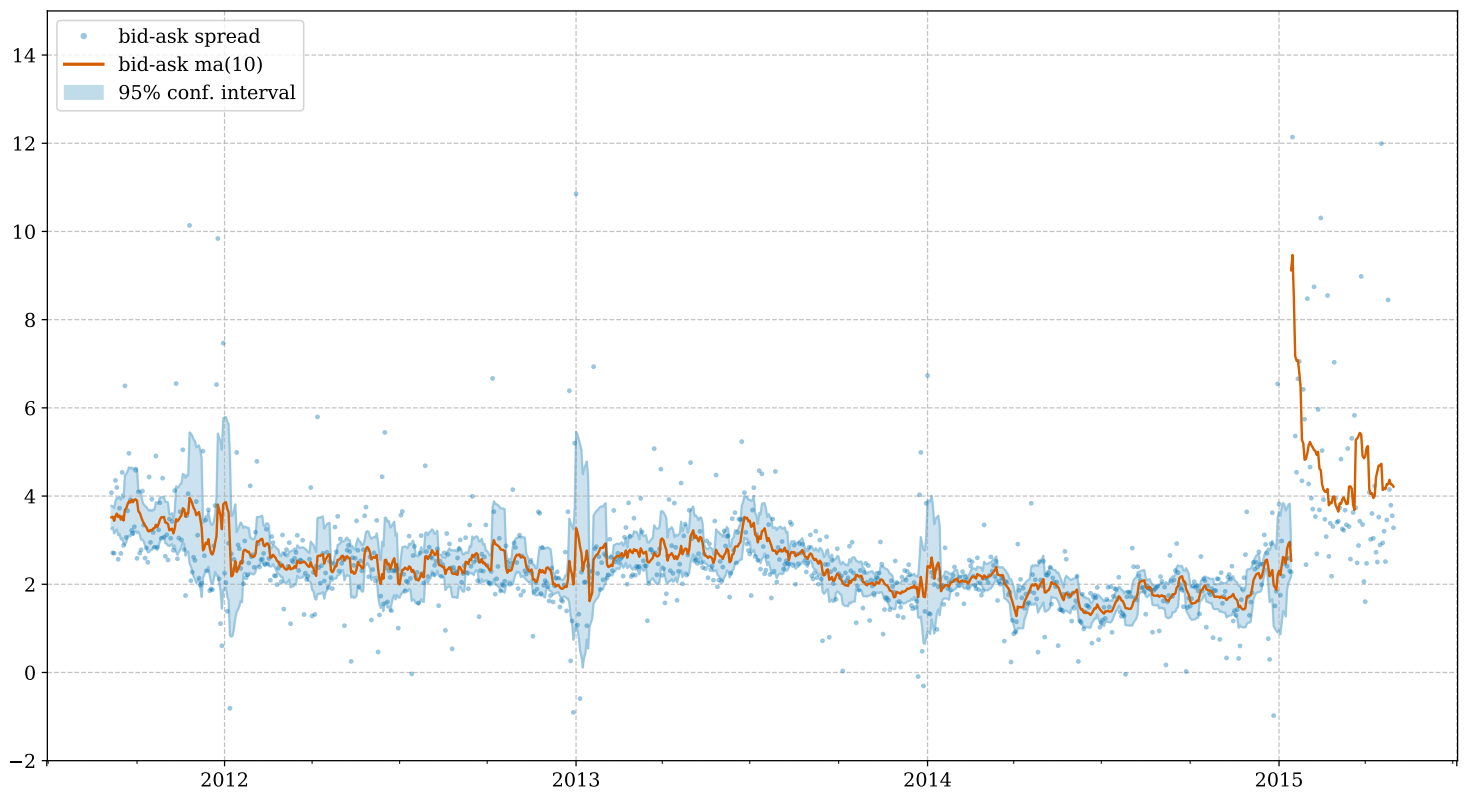


Figure 5: The dynamic effect of SNB's verbal interventions on uncertainty: an event study. The figure shows the cumulative average difference in uncertainty since the speech day (day 0) and the $95 \%$ confidence band around zero, for the 1-, 3-, 6-, 9- and 12-month horizon. The uncertainty at any given day is defined as the Black-Scholes implied volatility of the at-the-money call option observed on that day. The confidence interval is calculated assuming cross-sectional and intertemporal independence of differences in uncertainty.

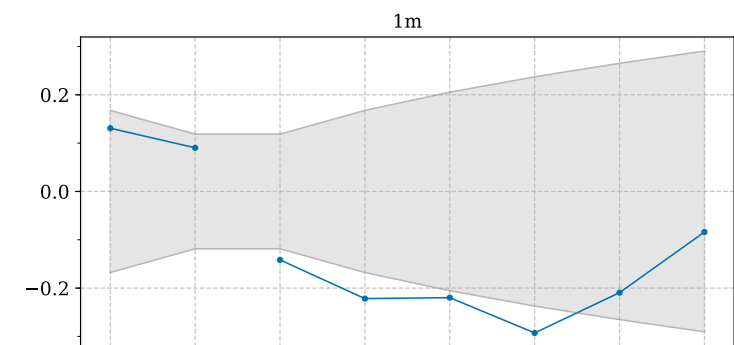

$6 \mathrm{~m}$
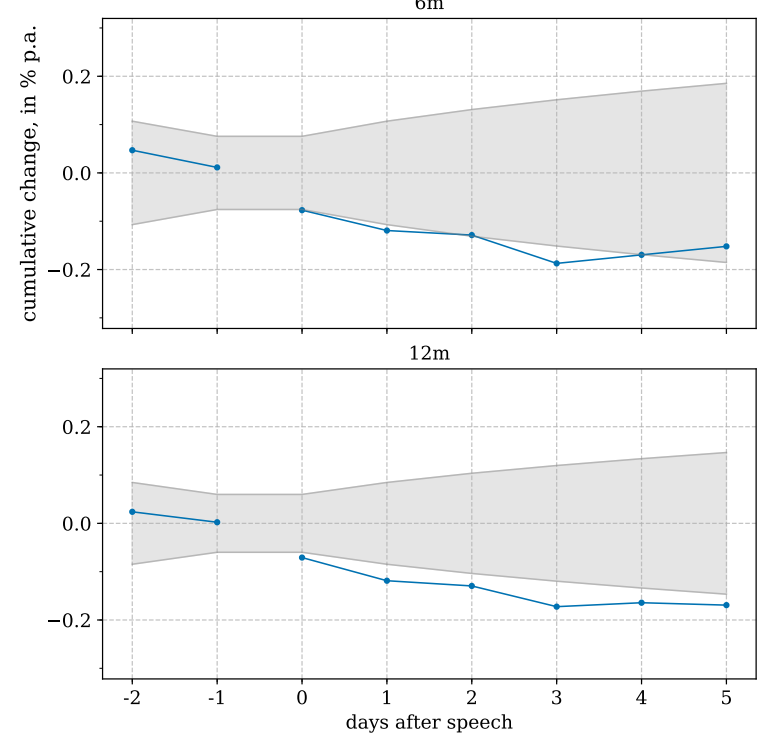

$3 \mathrm{~m}$

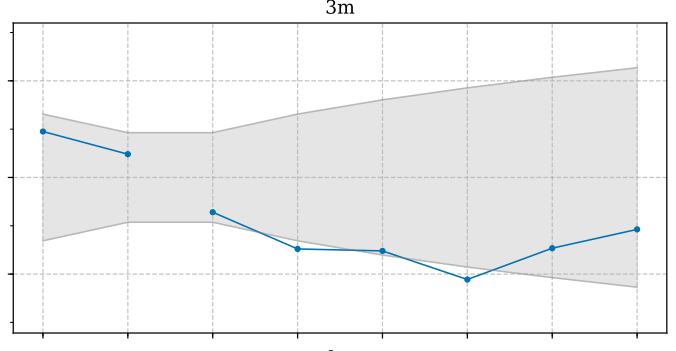

$9 \mathrm{~m}$

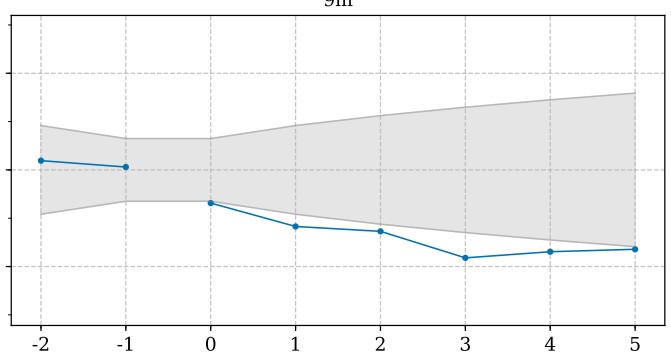


Figure 6: The dynamic effect of SNB's verbal interventions on skewness: an event study. The figure shows the cumulative average difference in skewness since the speech day (day 0) and the 95\% confidence band around zero, for the 1-, 3-, 6-, 9- and 12-month horizon. The skewness at any given day is defined as the average risk-reversal implied volatility observed on that day. The confidence interval is calculated assuming cross-sectional and intertemporal independence of differences in skewness.
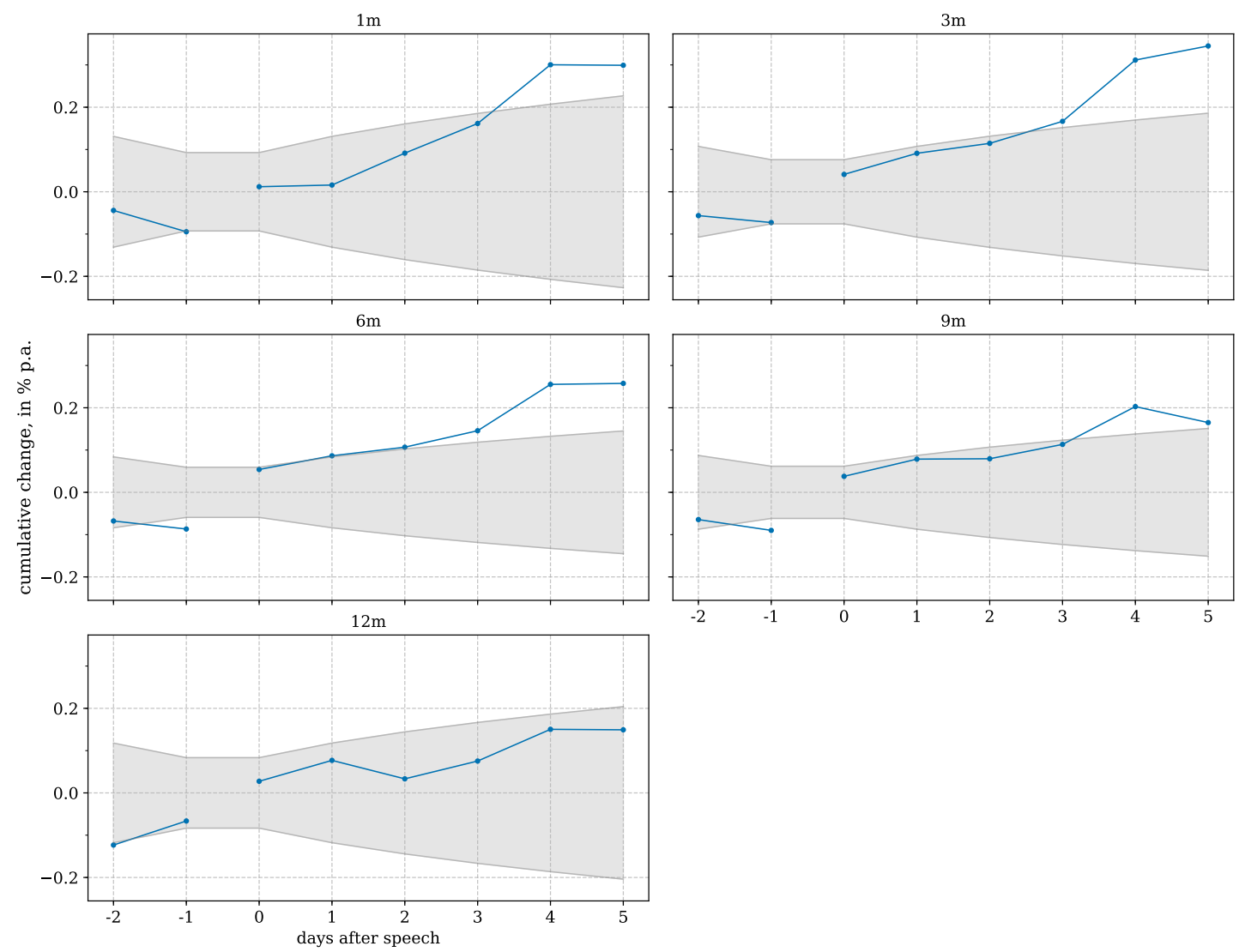
Figure 7: The effect of SNB's verbal interventions on uncertainty: separate effects for each date. The figure shows the regression coefficient with a $90 \%$ confidence band on SNB's verbal interventions. The dependent variable is 2-day change of uncertainty for the 3 month horizon. The regressors and the sample are the same as in Table 2, except that we add a dummy variable for intervention $i$. The figure illustrates the results from 26 regressions, setting $i=1$, then $i=2$, etc.

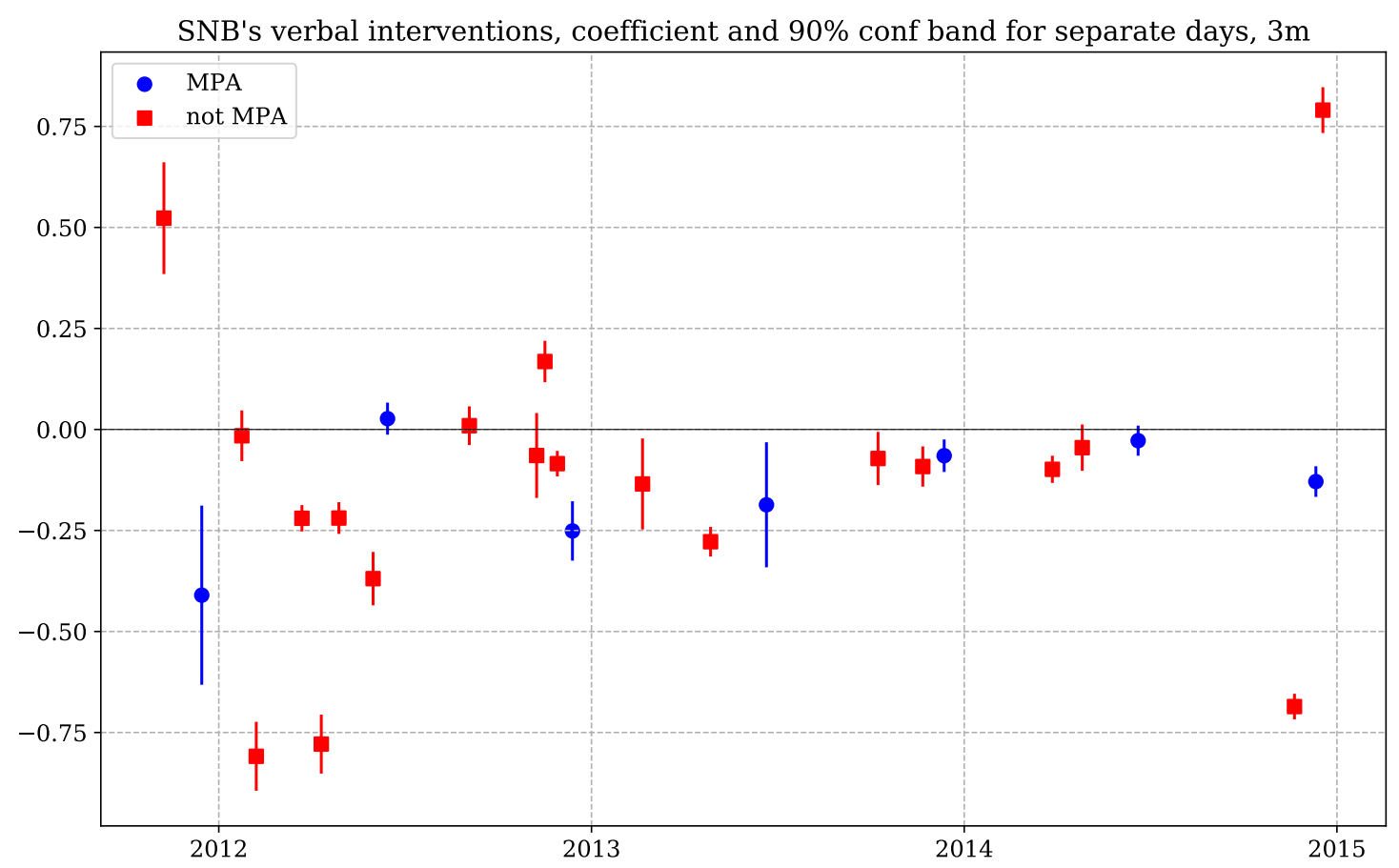

